\title{
The Effects of Smoking on Hair Health: A Systematic Review
}

\author{
Arash Babadjouni $^{\mathrm{a}, \mathrm{b}}$ Delila Pouldar Foulad ${ }^{\mathrm{a}}$ Bobak Hedayati $^{\mathrm{a}}$ Evyatar Evron $^{\mathrm{c}}$ \\ Natasha Mesinkovska ${ }^{a}$ \\ aDepartment of Dermatology, University of California Irvine, Irvine, CA, USA; ${ }^{b}$ Midwestern University - Arizona \\ College of Osteopathic Medicine, Glendale, AZ, USA; 'Department of Medicine, Cedars-Sinai Medical Center, \\ Los Angeles, CA, USA
}

\section{Keywords}

Smoking $\cdot$ Nicotine $\cdot$ Hair loss $\cdot$ Alopecia $\cdot$ Premature hair graying

\begin{abstract}
Smoking is not only a preventable cause of significant systemic disease but also affects the follicular growth cycle and fiber pigmentation. Ambient tobacco smoke exposure results in nicotine accumulation in hair follicles and the hair shaft. This review summarizes the evidence on the association between smoking and hair health, as denoted by alopecia and premature hair graying (PHG). In July 2020, a review of the literature using PubMed/MEDLINE and CINAHL databases identified 32 studies investigating the relationship between smoking, PHG, and alopecia (androgenetic alopecia and frontal fibrosing alopecia). The prevalence of hair loss and PHG is more prevalent in smokers than nonsmokers. Smoking is associated with negative effects on hair health as evidenced in PHG and alopecia. Smoking status should be assessed in patients who are presenting to their dermatologist for evaluation of alopecia and PHG.
\end{abstract}

(c) 2021 S. Karger AG, Basel

\section{Introduction}

Alopecia (hair loss) is a common chief complaint of patients' presenting to their dermatologist's and primary care providers [1]. The etiology of the most common type of alopecia, androgenetic alopecia (AGA), is multifactorial. Systemic androgens have been shown to play a role in the pathogenesis of AGA by causing hair miniaturization and transforming terminal to vellus hairs $[2,3]$. The role of environmental factors, such as smoking, has been implicated to negatively affect hair growth.

Smoking is a risk factor for many preventable morbidities, including cerebrovascular, pulmonary disease, malignancy, and oral mucocutaneous disease. More recently, the role of smoking in skin aging and hair loss has been a great topic of interest and research $[4,5]$. Animal studies in mice have indicated that environmental factors, including tobacco smoke exposure, can lead to alopecia and premature hair graying (PHG). Chemical components found in tobacco smoke, such as nicotine, are capable of accumulating in hair, and have become reliable biomarkers for detecting smoke exposure [6]. Smoking has also been shown to cause a relative hypo-estrogen state in women via hydroxylation of estradiol and inhibi-

Arash Babadjoun

Midwestern University - Arizona College of Osteopathic Medicine 19555 N 59th Ave.

Glendale, AZ 85308 (USA)

asbabadjouni@gmail.com 
tion of aromatase, thus potentially affecting androgendependent hair patterns [2].

Additional studies have also suggested a relationship between smoking and PHG $[3,4]$. Interestingly, in immunological staining studies of melanocytes in gray hair, melanosomes are found within vacuoles or autophagolysosomes, rendering them defective. In addition, hair bulbs exposed to oxidative stress tend to be increasingly vacuolated. This causes increased reactive oxygen species and oxidative stress around the follicle, leading to damage to melanocytes and decreased melanin production [5]. Currently, no universal criteria have been established to clinically diagnose $\mathrm{PHG}$, yet many have classified subjects by number of gray hairs $(0,<10,10-100,>100)$ and defined PHG as graying before the age of 30 -year old $[6,7]$. While hair graying is a normal physiological process associated with aging, PHG can decrease self-esteem and interfere with social and sexual communication, as noted by Akin et al. [6] where subjects with PHG were noted to have higher perceived stress scale scores.

The objective of this review was to investigate and report the evidence supporting the association between smoking and alopecia and premature graying. Evidence of this association can be used to clinically promote smoking cessation and emphasize the consequences of smoking on hair.

\section{Materials and Methods}

A primary literature review was conducted in July 2020 utilizing PubMed/MEDLINE and CINAHL databases with the following search terms: (Smoking OR tobacco OR nicotine) AND (Premature Graying OR Graying hair OR Hair color OR Hair Follicle OR Hair Loss OR Alopecia OR Hair OR Follicle OR Gray Hair). Exclusion criteria included studies that were written in languages other than English and studies not conducted on humans. Studies included for review were stratified using the Oxford Center for Evidence-Based Medicine 2011 Levels of Evidence.

\section{Results}

The systematic review identified 32 articles that met inclusion criteria including, 7 cross-sectional studies, 21 case-control, and 4 cohort studies ( $n=23,685$ patients) (Table 1). No randomized control trials were found. Ten studies investigated the association of smoking and alopecia, 8 articles studied the relationship between smoking and PHG, and 2 studies reported the effects of smoking on both. The majority of studies included patients with diagnosed AGA $(n=11,826)$ and frontal fibrosing alopecia (FFA) $(n=710)$ in association with smoking and nicotine use.

\section{Smoking and Alopecia}

The majority of epidemiologic studies recognize a positive association between smoking and alopecia, particularly in patients with AGA $[3,8-13,53]$. One surveybased study of 740 Asian men with a diagnosis of AGA reported that current smokers of twenty cigarettes or more per day, with a history of smoking, or those with a greater smoking intensity (defined as smoking duration $x$ amount per day) were at a higher risk of moderate or severe AGA (Norwood type IV) [8]. This study is in concordance with a study from the UK, which also found a link between quantity of smoking and AGA in patients $(n=268 \mathrm{M}, 338 \mathrm{~F})$ from a general surgery clinic $[3,7]$. A case-control study with 991 Korean AGA patients $(n=$ $613 \mathrm{M}, 378 \mathrm{~F}$ ) showed that current smokers experienced more severe cases of AGA when compared to noncurrent smokers. The subjects with a current smoking history had higher rate of U-type pattern alopecia according to the basic and specific classification system $(p=0.004)$ [9]. Twin studies on male $(n=92)$ and female $(n=98)$ patients with AGA conclude that increased pack-years of smoking was associated with more dramatic frontal hairline thinning $[10,11]$. The twin female smokers had increased temporal hair loss $(p=0.096 ; n=10)$, while male smokers had more vertex hair loss than nonsmokers $(p=0.047$, $n=20)$ [10,11]. A cross-sectional study conducted by Fortes et al. [12] focused specifically on severe cases of AGA and noted a 3 times greater risk of developing moderate/severe alopecia in those with a higher frequency of smoking ( $\geq 10$ cigarettes daily) $(n=351)$. A hospital-based cross-sectional study including 50 men with diagnosed early onset AGA (Norwood grade III or above developing before 36 years) and 50 case-controls reported a higher prevalence of smoking in subjects with AGA (52\%) compared to controls $(22 \%)(p=0.002)$ [13]. One propensitymatched retrospective study of 5,508 subjects from the Partners Healthcare Research Patient Data Repository revealed a higher frequency of current or past smokers (56.5\%) with alopecia areata compared to subjects with alopecia areata who have never smoked (42.6\%) [14]. Additionally, univariate analysis of 75 subjects with clinically diagnosed FFA, in a retrospective cross-sectional study, revealed a strong association between smoking and mild hairline recession $(p=0.128)$ [15]. A cross-sectional study including 1,000 male patients attending a dermatology clinic reported a greater prevalence of AGA among 


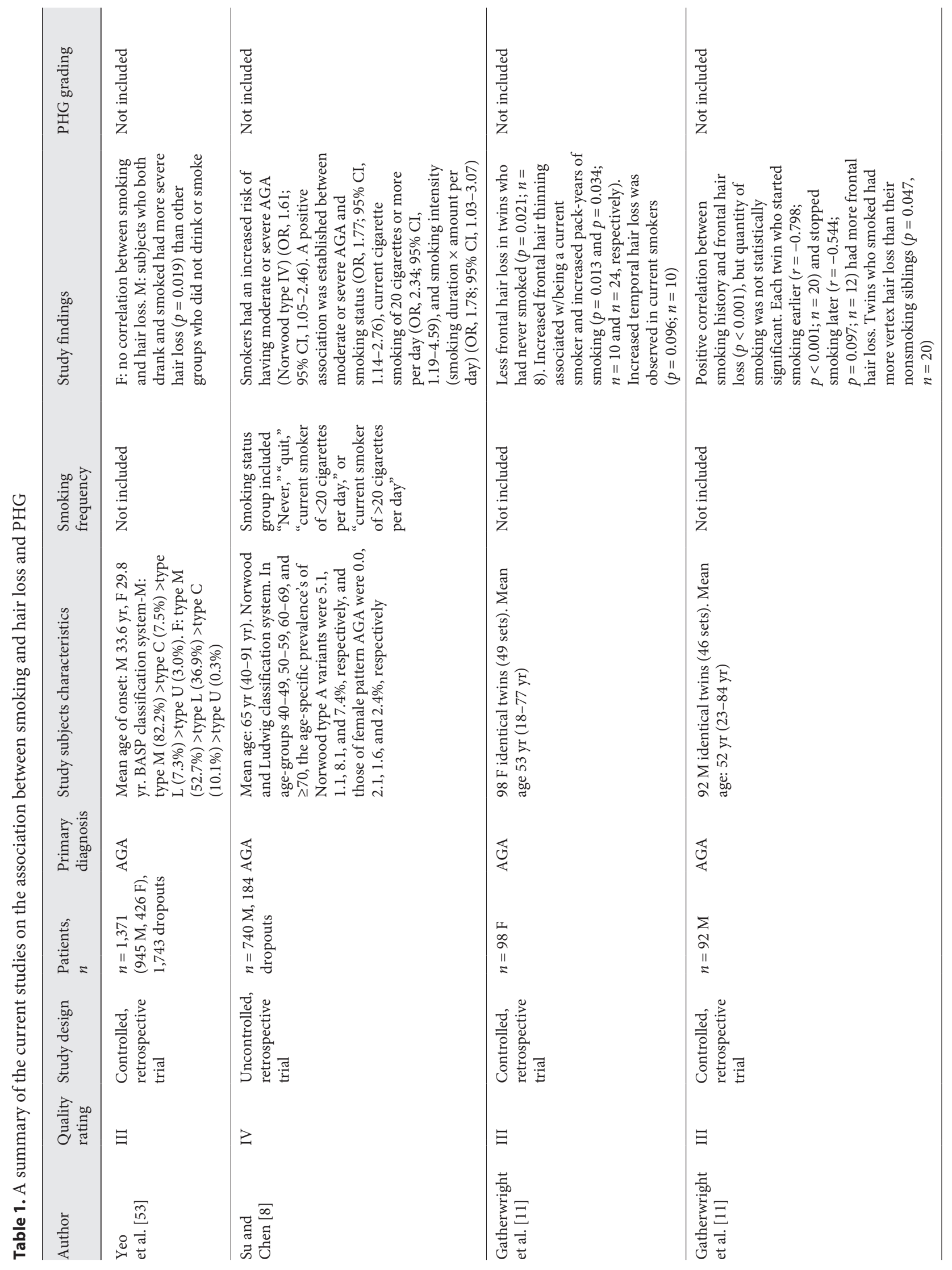




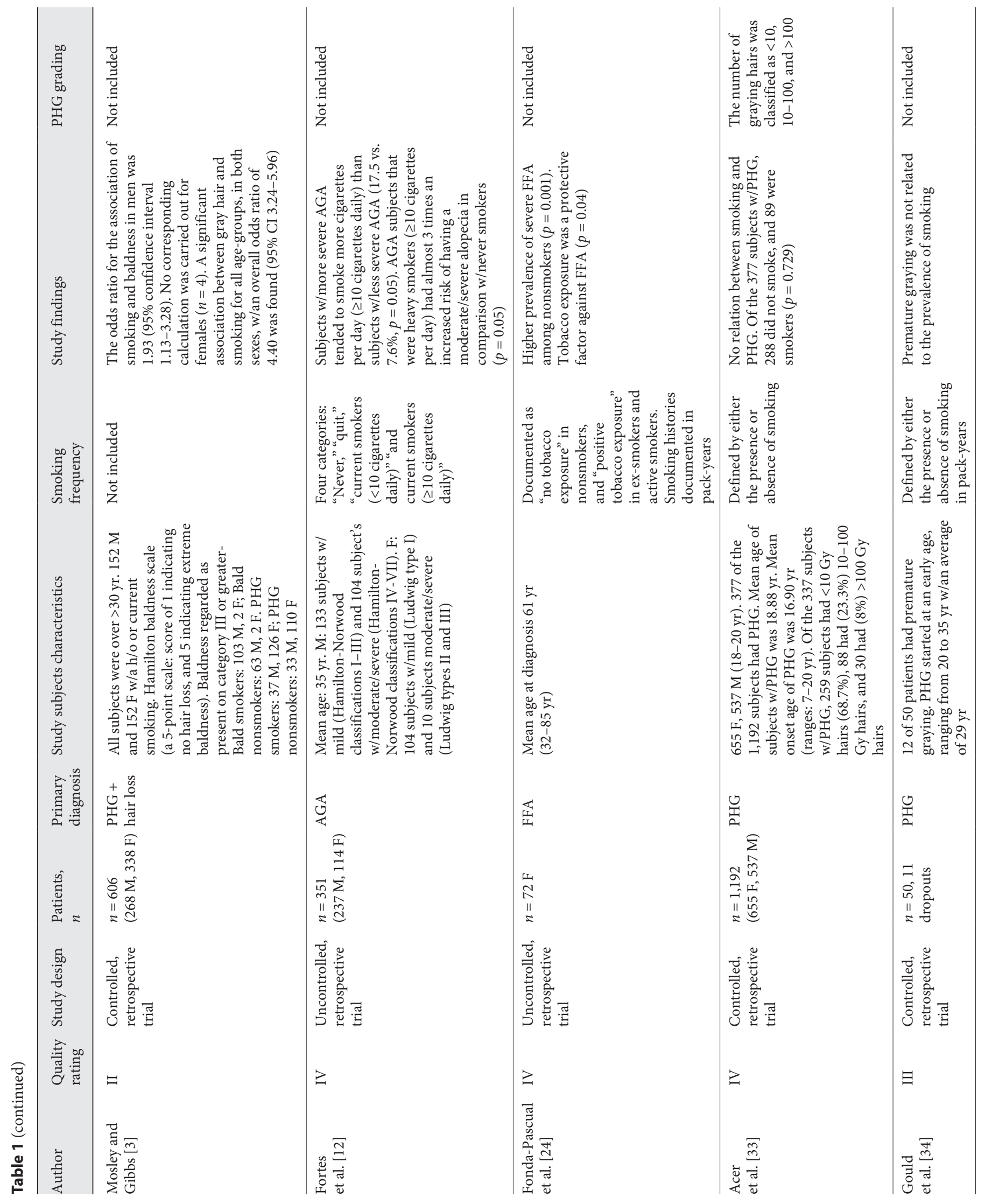




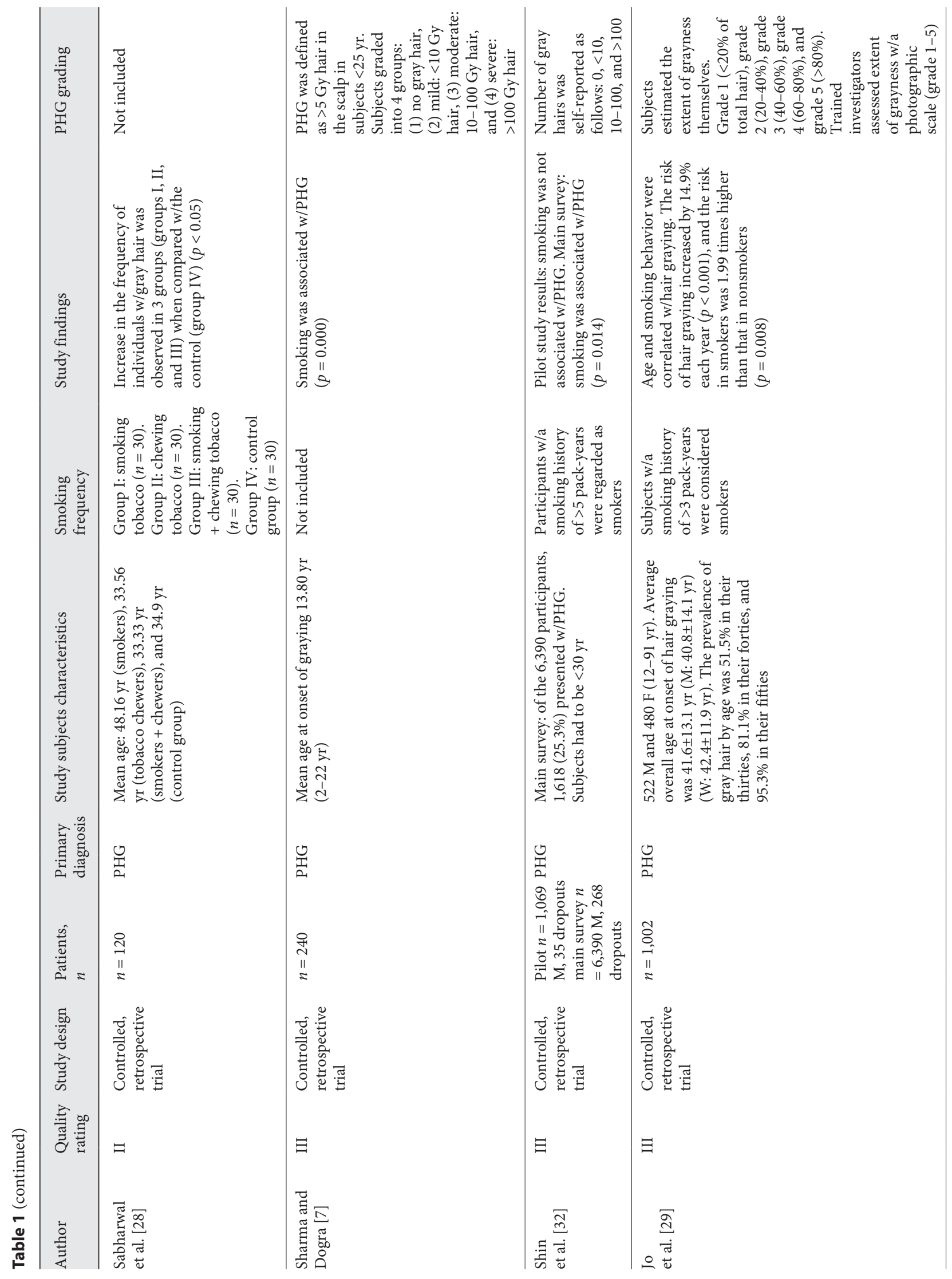




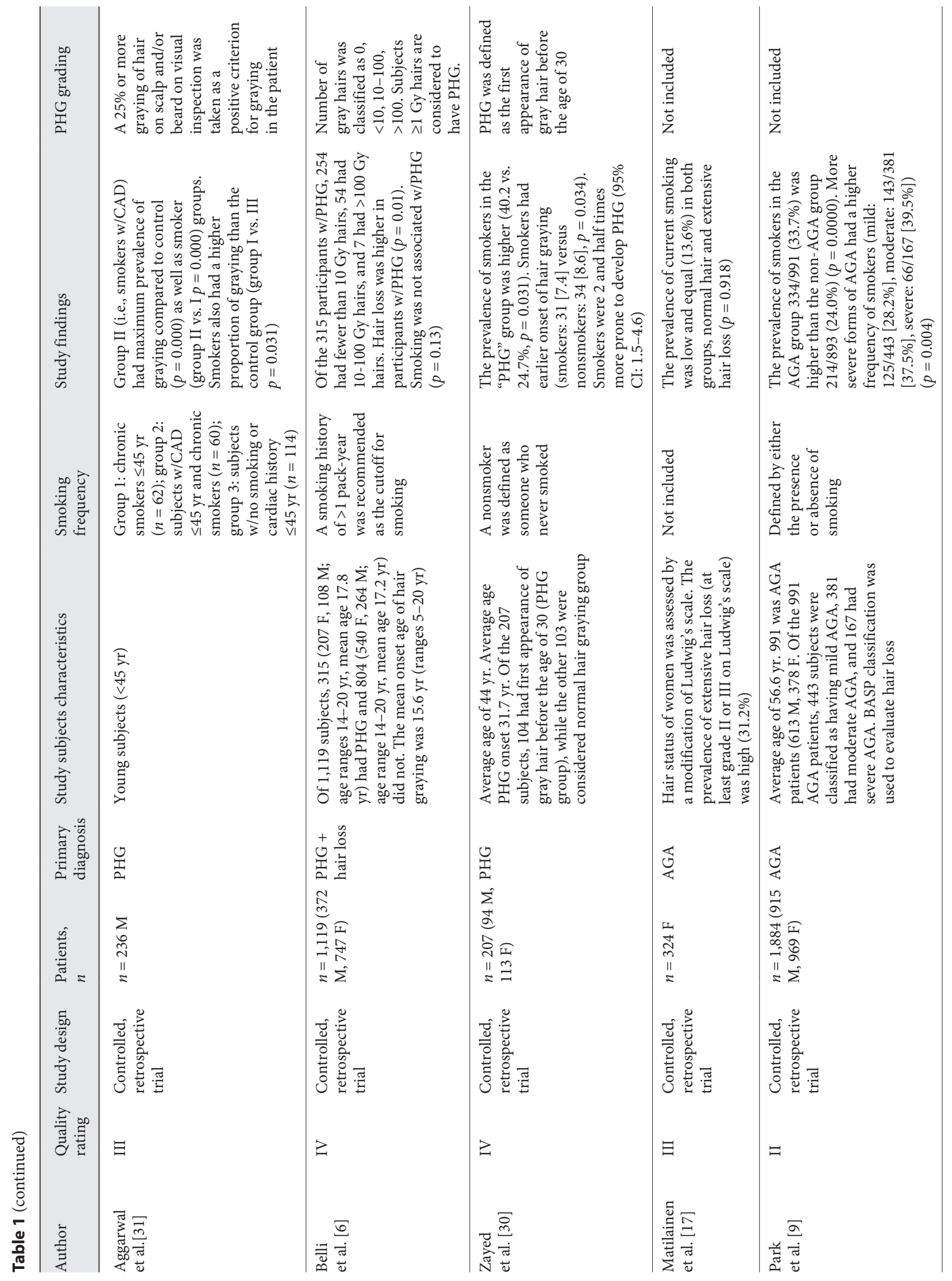




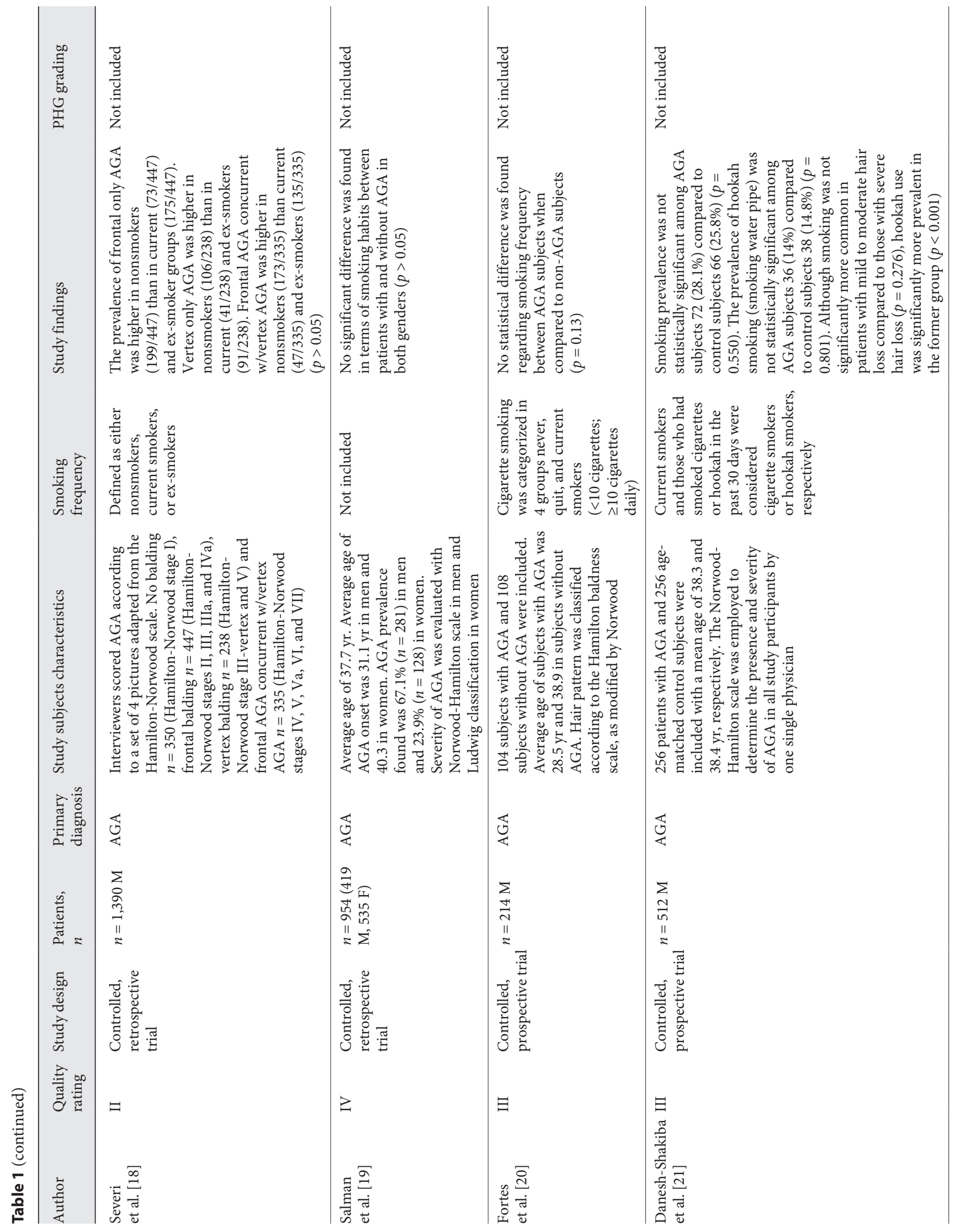




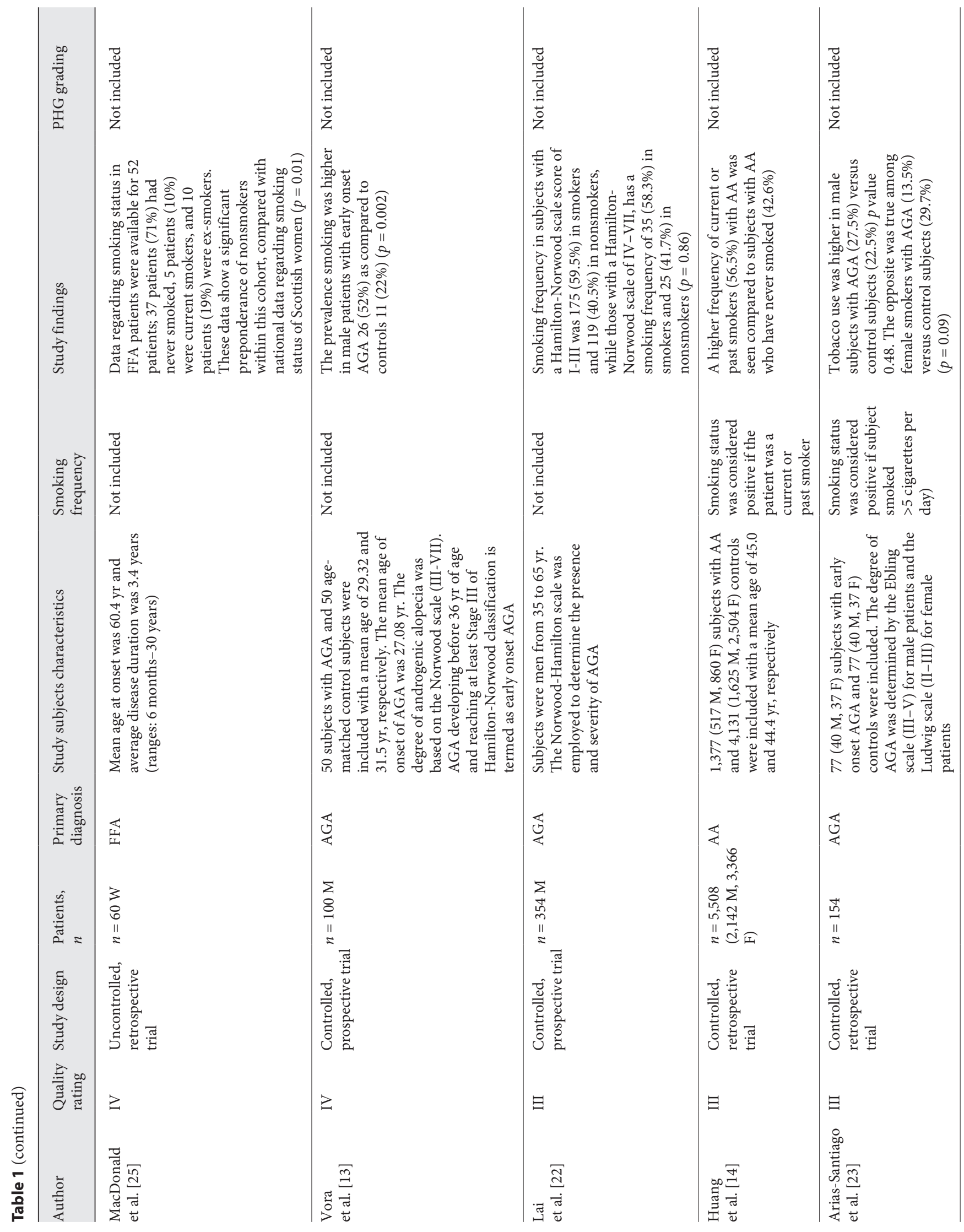




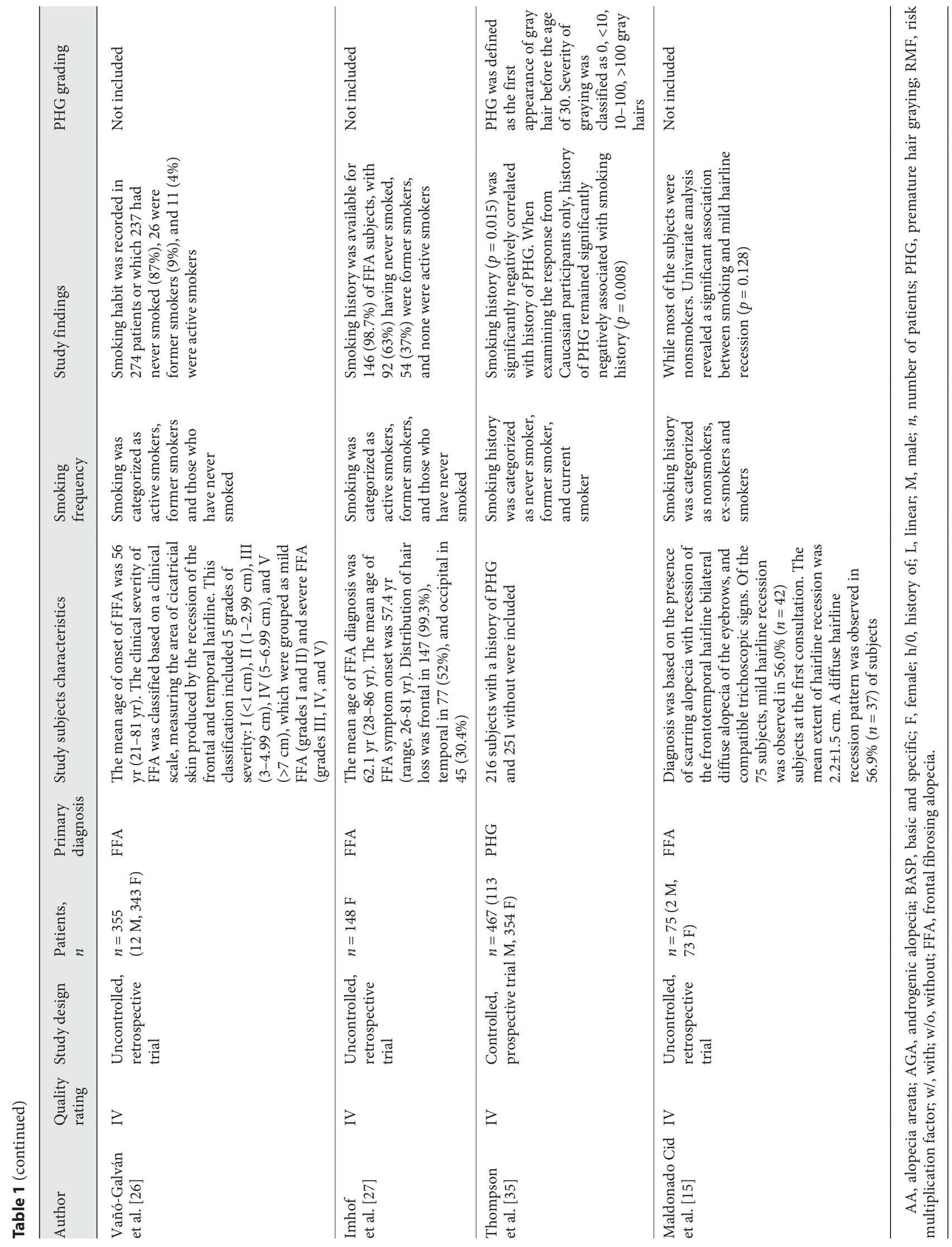


smokers, those who smoke $>10$ cigarettes per day and for more than a year, compared to nonsmokers $(p<0.001)$ [16]. Of the 500 smokers, $85 \%$ showed evidence of AGA, of which $47 \%$ had grade III AGA and $24 \%$ had grade IV AGA $(p<0.01)$ [16]. To a lesser extent, just $40 \%$ of 500 nonsmokers presented with AGA, with $20 \%$ of this group having grade II AGA and 10\% having either grade III or IV AGA $(p<0.01)[16]$.

Despite the high prevalence of extensive alopecia (31.2\%) among 324 Finnish women (average age 63 years), a cross-sectional cohort survey reported the prevalence of smoking was the same between those with extensive (Ludwig's scale II or greater) and minimal/normal alopecia in this group $(p=0.92)$ [17]. On the contrary, a large population-based case-control study on Australian men aged 40-69 years reported that subjects with lengthier smoking histories, irrespectively of being current or previous smokers, were less likely to develop AGA compared to nonsmokers $(n=1,390 \mathrm{M})$ [18]. This study suggests the previously proposed association between smoking and alopecia could instead be explained by an increased risk of smoking because of having AGA. Additionally, a cross-sectional case-control study including 954 subjects ( $419 \mathrm{M}, 535 \mathrm{~F})$ reported no significant difference in smoking habits between patients with AGA or controls, in both genders $(p>0.05)$ [19]. However, interpretation of the results from both studies was impacted by a lack of detail provided in the smoking history and age of AGA diagnosis [18, 19]. Questionnaire results from a hospital-based, controlled study reported no statistical difference in the frequency of subjects with or without AGA who were current smokers of $<10$ cigarettes per day $(n=214 \mathrm{M})(p=0.13)$ [20]. The study results are limited by the younger age of subjects with AGA (28.5 years) compared to controls (38.9 years), which may limit the generalizability of the results [20]. In a case-controlled study including 256 subjects with AGA and 256 agematched controls, no significant difference in cigarette smoking status was reported between subjects with or without AGA $(p=0.550)$. Additionally, the frequency of hookah (water pipe) smoking was similar between AGA $(14 \%)$ and healthy control $(14.8 \%)$ subjects $(p=0.801)$ [21]. Limitations of this study include a lack of detail provided in the smoking history and subjects with minimal cigarette or hookah smoking exposure, including any subject who had smoked in the past 30 days [21]. A casecontrolled prospective study including 354 men from ages 35-65 years failed to identify a statistically significant correlation between cigarette smoking and AGA in subjects with either a Hamilton-Norwood scale scores I-III or IV-VII [22]. However, this inconsistency with study's who report a significant correlation between smoking and AGA can be explained by differences in sampling methods, including balancing the ratios of smokers and nonsmokers in both AGA and control groups [22]. Similarly, a case-control study including 77 early onset AGA subjects and 77 healthy controls failed to report a significant increase in smoking history ( $>5$ cigarettes per day) in men $(p=0.48)$ or women $(p=0.09)$ [23]. These results are limited by a small sample size [23]. A cross-sectional retrospective study found that tobacco exposure had a protective role in the development of clinically diagnosed FFA in 1 Asian and 71 Caucasian female subjects. Compared to nonsmokers with severe FFA (frontal regression $\geq 3 \mathrm{~cm}$ ), this study reported a lower incidence of severe FFA in subjects with a smoking history of $>20$ pack-years, even after smoking cessation $(p=0.04)$. Notably, the study was limited by a small sample size and did not include an equivalent control group [24]. Additionally, 3 retrospective reviews, mainly including women $(12 \mathrm{M}$, $551 \mathrm{~F}$ ), failed to reveal a significant frequency of smoking in subjects with FFA [25-27]. MacDonald et al. [25] reported a high prevalence of nonsmokers $(71 \%)$ in a review of 60 cases of FFA, further suggesting the possible protective role smoking may play in developing FFA ( $p=$ 0.01). Additionally, Vañó-Galván et al. [26] reported a greater prevalence of nonsmokers (87\%) with FFA, in a review of 355 subjects from 12 Spanish centers. Similar results were published in a review of 148 women with FFA, which reported 92 (63\%) subjects having never smoked and no active smokers [27]. However, limitations seen in all 3 studies include their retrospective design and incomplete or short length of follow-up [25-27].

\section{Smoking and Premature Hair Graying}

A positive correlation between smoking and PHG, defined as presence of gray hair $<30$ years, was described in 7 studies [3, 7, 28-32]. In an observational study, Mosley and Gibbs [3] reported a higher incidence of hair graying in smokers over 30-year old than in nonsmokers regardless of age-group or gender $(n=606)$. Subjects, in an observational study, who were exposed to smoking tobacco, chewing tobacco, or a combination of the 2 , had a higher incidence of premature graying compared to controls $(n=120)$ [28]. Furthermore, a questionnaire in Korean patients ages 12-91 years reported a $14.9 \%$ increased risk of developing premature gray hair for every year a subject smokes ( $n=522 \mathrm{M}, 480 \mathrm{~F}, p<0.001)$, and an overall 1.99 times higher risk of graying prematurely compared to nonsmokers [29]. Premature graying in subjects with a 
reported history of smoking was also observed in a crosssectional study conducted by Zayed et al. [30] ( $n=207$, $p=0.031$ ), and a case-control study of chronic smokers compared to subjects with no smoking history $(n=236$, $p=0.031$ ) [31]. In 2 similar studies by Sharma and Dogra [7] and Shin et al. [32], a significant number of patients with PHG also confirmed a history of smoking, with a correlation reported with a minimum smoking history of 5 pack-years $(n=240)$.

On the contrary, 2 large cross-sectional studies evaluating the socio-clinical risk factors associated with PHG found no association seen between smoking history and PHG $[6,33]$. Both studies included subjects younger than 21 -year old with a limited smoking history including rate and duration of smoking [6,33]. Acer et al. [33] classified subjects as either current smokers or nonsmokers, while Belli et al. [6] required a smoking history of more than 1 pack-year to be considered a smoker. Questionnaire results from a third study reported no correlation between smoking history and PHG due to a similar incidence of smoking, between ages 20 - and 35-year old $(n=50)$ [34]. Similarly, a more recent case-controlled survey study found a negative association between smoking history (defined as never, former, and current smokers) and PHG $(0,1-10,11-100$, and $>100$ self-reported gray hairs beginning age $\leq 30)(n=467)$ [35]. This discrepancy with previous studies that report a significant association between smoking and PHG can be explained by the use of chronological smoking history (never, former, and current) rather than quantity of smoking [35]. Also, participants' responses and results of survey studies may be subject to recall bias $[34,35]$. Unlike the hair loss controversy, there are no studies that support a protective role for smoking or nicotine and hair graying.

\section{Discussion}

While genetic factors play an important role in alopecia and PHG, environmental factors, including smoking and nicotine exposure, should be taken into consideration. The current scientific evidence drawn foremost from cross-sectional studies shows a positive correlation between the length of smoking history and alopecia severity in patients with AGA $[10,11,16]$. Severe presentations of AGA were observed in subjects who smoked a larger quantity of cigarettes per day $[8,10-13]$. Several studies reported no association between smoking and alopecia [17-27]. Among these, a cross-sectional retrospective study reported a higher prevalence of scarring alopecia, severe FFA, in subjects with no previous tobacco exposure [24]. Several hormonal deregulations, including decreased prolactin, have been linked to chronic tobacco exposure and may explain the higher prevalence of FFA among nonsmokers.

A possible association between female androgenetic alopecia (FAA) and acute telogen effluvium has been observed in previous studies [36, 37]. Furthermore, a retrospective analysis has identified triggering causes, such as iron deficiency and thyroid dysfunction, which hold a greater risk of developing concurrent FAA and acute telogen effluvium [38]. Also, a report has provided support that some cases of telogen effluvium may rapidly progress to FAA [39].

An earlier onset and higher prevalence of hair graying were also observed in smoker groups compared to controls $[7,28,30,31]$. A positive smoking history was also shown to increase the risk of hair graying each year a subject continued to smoke [29]. This correlation was not found to be true for smokers under the age of 21-year old, presumably because of shorter duration of smoking and time frame of study $[6,33,34]$.

While the mechanism responsible for hair loss in subjects exposed to nicotine or tobacco smoke is unknown, it is thought to be similar to the mechanism by which smoking increases skin aging. Nicotine is known to cause constriction of dermal hair papilla and local ischemia, accumulation of DNA damage, dysregulation of protease/ antiprotease systems involved in the hair growth cycle, and upregulation of local pro-inflammatory cytokines implicated in follicular inflammation and fibrosis [40, 41]. A hypothesis exists that exogenous nicotine from smoking can cause overstimulation of the cellular nicotinic acetylcholine receptors leading to desensitization of the receptor. This in turn contributes to hair follicle destruction by activation of programmed cell death pathways present in keratinocytes [42-44].

Studies in C57BL/6 mice, a strain prone to hair loss, may hold the explanation for increased hair loss in subjects who smoke. When the mice were exposed to wholebody, environmental tobacco smoke (ETS) for 3 months, they showed evidence of hair loss and PHG, with circular alopecic patches and graying reported on their backs [45]. The patches grew larger with longer ETS exposure, and at 4 months, all ETS-exposed mice had developed irregular and scattered regions of gray hair. Neither hair loss nor PHG was observed in the control group. On histology, alopecic areas showed fewer and shorter hair follicles and diminished hair bulbs with decreased and irregular pigmentation, with markers of cellular apoptosis. These 
findings were thought to be secondary to metabolic changes induced by inhaled smoke-associated genotoxins leading to a dystrophic anagen pattern $[45,46]$

Long-term, high-dose nicotine treatment on $\mathrm{A} / \mathrm{J}$ mouse models commonly used to investigate the carcinogenic effects of nitrosamines, a downstream metabolite produced by the nitrosation of nicotine, are related to hair loss [47-49]. Mice treated with subcutaneous injection of nicotine daily, after 8-9 months of treatment, started to lose hair in discrete patches. Another study in rats infused with nicotine showed evidence of hair follicle fibrosis, chronic inflammatory infiltrate, and extravasation of erythrocytes [50].

The image of health is negatively impacted by hair loss and graying [51, 52]. More recently, "smokeless tobacco" products have been heavily marketed, but these too contain high dosages of nicotine, and this new and growing trend may also pose a substantial risk to hair health.

This review was limited by a lack of randomized control trials or case-series in the literature, reports of association rather than causation, lack of scalp biopsies to confirm a link between smoke-induced oxidative stress and AGA, and recall bias due to the use of questionnaires. Also, the use of small sample sizes and hospital- or outpatient-based rather than community-based studies make it difficult to generalize the data to the general population. Results supporting no association between smoking and hair loss could not be accurately interpreted due to small sample size, incomplete smoking histories, and inequivalent control groups $[17,18,24]$. Reports that failed to demonstrate and association between smoking and PHG were limited by young subjects under 21-year old $[6,33,34]$.

\section{References}

1 Phillips TG, Slomiany WP, Allison R. Hair loss: common causes and treatment. Am Fam Physician. 2017 Sep 15 [cited 2019 Jun 21]; 96(6):371-8.

2 Skurnik Y, Shoenfeld Y. Health effects of cigarette smoking. Clin Dermatol. 1998 [cited 2019 Jun 10];16(5):545-56.

3 Mosley JG, Gibbs ACC. Premature grey hair and hair loss among smokers: a new opportunity for health education? BMJ. 1996 Dec 21 [cited 2019 Jun 10];313(7072):1616.

\section{Conclusion}

In addition to a wide variety of systemic and cutaneous health concerns, an association exists between smoking and alopecia as well as smoking and PHG. While there is more evidence in AGA, the reports in FFA are controversial. Dermatologist and physicians alike have an additional role in promoting smoking cessation by offering an opinion on the detrimental effects of smoking on hair [41]. Further studies, notably randomized controlled trials, should be conducted to assess for causality and to further investigate the mechanism of action responsible for this phenomenon.

\section{Acknowledgement}

The authors do not have any acknowledgments to disclose.

\section{Conflict of Interest Statement}

The authors do not have any conflicts of interest to report.

\section{Funding Sources}

The authors do not have funding to disclose.

\section{Author Contributions}

Arash Babadjouni was responsible for reviewing the literature, analyzing the data collected, and writing the final review. Dr. Natasha Mesinkovska, Dr. Delila Pouldar Foulad, Bobak Hedayati, and Dr. Evyatar Evron were involved in formulating the initial study design and editing the final review.
4 Mahendiratta S, Sarma P, Kaur H, Kaur S, Kaur H, Bansal S, et al. Premature graying of hair: risk factors, co-morbid conditions, pharmacotherapy and reversal: a systematic review and meta-analysis. Dermatol Ther. 2020 Jul 11 [cited 2020 Aug 3]:e13990.

5 Trüeb RM. Pharmacologic interventions in aging hair. Clin Interv Aging. 2006 [cited 2019 Jun 10];1(2):121-9.

6 Belli AA, Etgu F, Ozbas Gok S, Kara B, Dogan G. Risk factors for premature hair graying in young Turkish adults. Pediatr Dermatol. 2016 Jul [cited 2019 Jun 10];33(4):438-42.
7 Sharma N, Dogra D. Association of epidemiological and biochemical factors with premature graying of hair: a case-control study. Int J Trichology. 2018 [cited 2019 Jun 11];10(5): 211-7.

$8 \mathrm{Su}$ L-H, Chen TH-H. Association of androgenetic alopecia with smoking and its prevalence among Asian men. Arch Dermatol. 2007 Nov 1 [cited 2019 Jun 10];143(11):14016.

Babadjouni/Pouldar Foulad/Hedayati/ Evron/Mesinkovska 
9 Park SY, Oh SS, Lee WS. Relationship between androgenetic alopecia and cardiovascular risk factors according to BASP classification in Koreans. J Dermatol. 2016 Nov [cited 2019 Jun 10];43(11):1293-300.

10 Gatherwright J, Liu MT, Amirlak B, Gliniak C, Totonchi A, Guyuron B. The contribution of endogenous and exogenous factors to male alopecia: a study of identical twins. Plast Reconstr Surg. 2013 May [cited 2019 Jun 10]; 131(5):794e-801e.

11 Gatherwright J, Liu MT, Gliniak C, Totonchi A, Guyuron B. The contribution of endogenous and exogenous factors to female alopecia: a study of identical twins. Plast Reconstr Surg. 2012 Dec [cited 2019 Jun 10];130(6): 1219-26.

12 Fortes C, Mastroeni S, Mannooranparampil TJ, Ribuffo M. The combination of overweight and smoking increases the severity of androgenetic alopecia. Int J Dermatol. 2017 Aug [cited 2019 Jun 10];56(8):862-7.

13 Vora R, Kota RKK, Singhal R, Anjaneyan G. Clinical profile of androgenic alopecia and its association with cardiovascular risk factors. Indian J Dermatol. 2019 Jan 1;64(1):19-22.

14 Huang KP, Joyce CJ, Topaz M, Guo Y, Mostaghimi A. Cardiovascular risk in patients with alopecia areata (AA): a propensitymatched retrospective analysis. J Am Acad Dermatol. 2016 Jul 1 [cited 2020 Mar 30]; 75(1):151-4.

15 Maldonado Cid P, Leis Dosil VM, Garrido Gutiérrez C, Salinas Moreno S, Thuissard Vasallo IJ, Andreu Vázquez C, et al. Frontal fibrosing alopecia: a retrospective study of 75 patients. Actas Dermosifiliogr. 2020 Jul-Aug [cited 2020 Aug 3];111(6):487-95.

16 Salem AS, Ibrahim HS, Abdelaziz HH, Elsaie ML. Implications of cigarette smoking on early onset androgenetic alopecia: a cross sectional study. J Cosmet Dermatol. 2020 Sep 18 [cited 2020 Sep 23].

17 Matilainen V, Laakso M, Hirsso P, Koskela P, Rajala U, Keinänen-Kiukaanniemi S. Hair loss, insulin resistance, and heredity in middle-aged women. A population-based study. J Cardiovasc Risk. 2003 Jun 1 [cited 2019 Jun 10];10(3):227-31.

18 Severi G, Sinclair R, Hopper JL, English DR, McCredie MR, Boyle P, et al. Androgenetic alopecia in men aged 40-69 years: prevalence and risk factors. Br J Dermatol. 2003 Dec [cited 2019 Jun 10];149(6):1207-13.

19 Salman KE, Altunay IK, Kucukunal NA, Cerman AA. Frequency, severity and related factors of androgenetic alopecia in dermatology outpatient clinic: hospital-based cross-sectional study in Turkey. An Bras Dermatol. 2017 Jan 1 [cited 2020 Mar 30];92(1):35-40.

20 Fortes C, Mastroeni S, Mannooranparampil T, Abeni D, Panebianco A. Mediterranean diet: fresh herbs and fresh vegetables decrease the risk of androgenetic alopecia in males. Arch Dermatol Res. 2018 Jan 1 [cited 2020 Mar 30];310(1):71-6.
21 Danesh-Shakiba M, Poorolajal J, Alirezaei P. Androgenetic alopecia: relationship to anthropometric indices, blood pressure and lifestyle habits. Clin Cosmet Investig Dermatol. 2020 [cited 2020 Mar 30];13:137-43.

22 Lai CH, Chu NF, Chang CW, Wang SL, Yang $\mathrm{HC}$, Chu CM, et al. Androgenic alopecia is associated with less dietary soy, lower [corrected] blood vanadium and rs1160312 1 polymorphism in Taiwanese communities. PLoS One. 2013 Dec 30 [cited 2020 Mar 30];8(12): e79789.

23 Arias-Santiago S, Gutiérrez-Salmerón MT, Castellote-Caballero L, Buendía-Eisman A, Naranjo-Sintes R. Androgenetic alopecia and cardiovascular risk factors in men and women: a comparative study. J Am Acad Dermatol. 2010 Sep [cited 2020 Mar 30];63(3):420-9.

24 Fonda-Pascual P, Saceda-Corralo D, Moreno-Arrones OM, Alegre-Sanchez A, VañoGalvan S. Frontal fibrosing alopecia and environment: may tobacco be protective? J Eur Acad Dermatol Venereol. 2017 Feb [cited 2019 Jun 10];31(2):e98-9.

25 MacDonald A, Clark C, Holmes S. Frontal fibrosing alopecia: a review of 60 cases. J Am Acad Dermatol. 2012 Nov [cited 2020 Mar 30];67(5):955-61.

26 Vañó-Galván S, Molina-Ruiz AM, SerranoFalcón C, Arias-Santiago S, Rodrigues-Barata AR, Garnacho-Saucedo G, et al. Frontal fibrosing alopecia: a multicenter review of 355 patients. J Am Acad Dermatol. 2014 [cited $2020 \mathrm{Jul} 28] ; 70(4): 670-8$.

27 Imhof RL, Chaudhry HM, Larkin SC, Torgerson RR, Tolkachjov SN. Frontal fibrosing alopecia in women: the mayo clinic experience with 148 patients, 1992-2016. Mayo Clin Proc. 2018 Nov 1 [cited 2020 Jul 28];93(11): $1581-8$.

28 Sabharwal R, Gupta A, Moon N, Mahendra A, Sargaiyan V, Gupta A, et al. Association between use of tobacco and age on graying of hair. Niger J Surg. 2014 Jul [cited 2019 Jun 10]; 20(2):83-6.

29 Jo SJ, Paik SH, Choi JW, Lee JH, Cho S, Kim $\mathrm{KH}$, et al. Hair graying pattern depends on gender, onset age and smoking habits. Acta Derm Venereol. 2012 Mar [cited 2019 Jun 10];92(2):160-1.

30 Zayed A, Shahait A, Ayoub M, Yousef AM. Smokers' hair: does smoking cause premature hair graying? Indian Dermatol Online J. 2013 Apr [cited 2019 Jun 10];4(2):90.

31 Aggarwal A, Srivastava S, Agarwal MP Dwivedi S. Premature graying of hair: an independent risk marker for coronary artery disease in smokers: a retrospective case control study. Ethiop J Health Sci. 2015 Apr 21 [cited 2019 Jun 11];25(2):123-8.

32 Shin H, Ryu HH, Yoon J, Jo S, Jang S, Choi M, et al. Association of premature hair graying with family history, smoking, and obesity: a cross-sectional study. J Am Acad Dermatol. 2015 Feb [cited 2019 Jun 11];72(2):321-7.
33 Acer E, Kaya Erdoğan H, İğrek A, Parlak H, Saraçoğlu ZN, Bilgin M. Relationship between diet, atopy, family history, and premature hair graying. J Cosmet Dermatol. 2019 Apr 16 [cited 2019 Jun 10];18(2):665-70.

34 Gould L, Reddy CVR, Oh KC, Kim SG, Becker W. Premature hair graying: a probable coronary risk factor. Angiology. 1978 Nov 2 [cited 2019 Jun 10];29(11):800-3.

35 Thompson KG, Marchitto MC, Ly BCK, Chien AL. Evaluation of physiological, psychological, and lifestyle factors associated with premature hair graying. Int $J$ Trichology. 2019 Jul-Aug Jul 1 [cited 2020 Aug 3];11(4): $153-8$.

36 Whiting DA. Chronic telogen effluvium: increased scalp hair shedding in middle-aged women. J Am Acad Dermatol. 1996 [cited 2020 Aug 5];35(6):899-906.

37 Rebora A, Guarrera M, Baldari M, Vecchio F. Distinguishing androgenetic alopecia from chronic telogen effluvium when associated in the same patient: a simple noninvasive method. Arch Dermatol. 2005 Oct [cited 2020 Aug 5];141(10):1243-5.

38 Perez-Mora N, Goren A, Velasco C, Bermudez F. Acute telogen effluvium onset event is associated with the presence of female androgenetic alopecia: potential therapeutic implications. Dermatol Ther. 2014 [cited 2020 Aug 5];27(3):159-62.

39 Sinclair R. Chronic telogen effluvium or early androgenetic alopecia? Int J Dermatol. 2004 Nov [cited 2020 Aug 5];43(11):842-3. http:// dx.doi.org/10.1111/j.1365-4632.2004.02034.x.

40 Trüeb RM. Association between smoking and hair loss: another opportunity for health education against smoking? Dermatology. 2003 [cited 2019 Jun 10];206(3):189-91.

41 Freiman A, Bird G, Metelitsa AI, Barankin B, Lauzon GJ. Cutaneous effects of smoking. J Cutan Med Surg. 2004 Nov 5 [cited 2019 Jun $10] ; 8(6): 415-23$.

42 Yang X, Buccafusco JJ. Effect of chronic central treatment with the acetylcholine analog methylcarbamylcholine on cortical nicotinic receptors: correlation between receptor changes and behavioral function. J Pharmacol Exp Ther. 1994 Nov [cited 2019 Jun 19]; 271(2):651-9.

43 Zia S, Ndoye A, Nguyen VT, Grando SA. Nicotine enhances expression of the alpha 3 , alpha 4 , alpha 5, and alpha 7 nicotinic receptors modulating calcium metabolism and regulating adhesion and motility of respiratory epithelial cells. Res Commun Mol Pathol Pharmacol. 1997 Sep [cited 2019 Jun 19];97(3): 243-62.

44 Nguyen VT, Ndoye A, Hall LL, Zia S, Arredondo J, Chernyavsky AI, et al. Programmed cell death of keratinocytes culminates in apoptotic secretion of a humectant upon secretagogue action of acetylcholine. J Cell Sci. 2001 Mar [cited 2019 Jun 10];114(Pt 6):1189_ 204. 
45 D’Agostini F, Balansky R, Pesce C, Fiallo P, Lubet RA, Kelloff GJ, et al. Induction of alopecia in mice exposed to cigarette smoke. Toxicol Lett. 2000 Apr 3 [cited 2019 Jun 10]; 114(1-3):117-23.

46 Merk HF, Mukhtar H, Kaufmann I, Das M, Bickers DR. Human hair follicle benzo[a]pyrene and benzo[a]pyrene 7,8-diol metabolism: effect of exposure to a coal tar-containing shampoo. J Invest Dermatol. 1987 Jan 1 [cited 2019 Jun 11];88(1):71-6.

47 Galitovskiy V, Chernyavsky AI, Edwards RA, Grando SA. Muscle sarcomas and alopecia in A/J mice chronically treated with nicotine. Life Sci. 2012 Nov 27 [cited 2019 Jun 10]; 91(21-22):1109-12.
48 Stepanov I, Carmella SG, Han S, Pinto A, Strasser AA, Lerman C, et al. Evidence for endogenous formation of $\mathrm{N}^{\prime}$-nitrosonornicotine in some long-term nicotine patch users. Nicotine Tob Res. 2009 Jan [cited 2019 Jun 23]; 11(1):99-105.

49 Hecht SS. Biochemistry, biology, and carcinogenicity of tobacco-specific $\mathrm{N}$-nitrosamines. Chem Res Toxicol. 1998 Jun [cited 2019 Jun 23];11(6):559-603.

50 Inalöz HS, Inalöz SS, Deveci E, Eralp A. Teratogenic effects of nicotine on rat skin. Clin Exp Obstet Gynecol. 2000 [cited 2019 Jun 23]; 27(3-4):241-3.
51 Cash TF. The psychological effects of androgenetic alopecia in men. J Am Acad Dermatol. 1992 Jun [cited 2019 Jun 10];26926(6):92631.

52 Cash TF, Price VH, Savin RC. Psychological effects of androgenetic alopecia on women: comparisons with balding men and with female control subjects. J Am Acad Dermatol. 1993 Oct [cited 2019 Jun 10];29(4):568-75.

53 Yeo IK, Jang WS, Min PK, Cho HR, Cho SW, Hong NS, et al. An epidemiological study of androgenic alopecia in 3,114 Korean patients. Clin Exp Dermatol. 2014;39(1):25-9. 